\title{
Prioritisation and the initiation of HCC surveillance in CHB patients: lessons to learn from the COVID-19 crisis
}

\author{
Georgia Zeng, ${ }^{1}$ Upkar S Gill, ${ }^{2}$ Patrick T F Kennedy ${ }^{2}{ }^{2}$
}

\section{PREMISE}

COVID-19 was declared a pandemic by WHO in March 2020 resulting in an unprecedented strain on healthcare systems globally. ${ }^{1}$ Currently, there is no proven treatment for severe acute respiratory syndrome coronavirus 2 (SARS-CoV-2, which can cause serious disease with an associated high mortality in a proportion of patients. ${ }^{2}$ The impact of COVID-19 was first seen in the Chinese healthcare system, but the experiences of Italy, France, Spain, the UK and now the USA underline the gravity of the crisis and the challenge that healthcare professionals will have to overcome globally. ${ }^{3-5}$

The current pandemic has impacted the management of almost all patients and those with chronic liver disease are no exception. These are uncertain times for both patients and healthcare professionals, while we adjust to the threat posed by COVID-19. An area of specific concern for us is how best to provide hepatocellular carcinoma (HCC) surveillance in chronic hepatitis B (CHB) patients and importantly, how we will prioritise patients for HCC screening at a time of limited resources, concern over potential nosocomial transmission and strict social distancing. While new guidance in relation to COVID-19 suggests that HCC surveillance can be deferred, ${ }^{67}$ it is accepted that patients with cirrhosis, elevated serum alpha-feto protein (AFP) and those with CHB among others should be prioritised. However, we feel that this may also represent an opportunity to review and streamline the risk stratification of $\mathrm{CHB}$ patients in whom, and when, we offer HCC surveillance. In this article, we outline the pertinent clinical aspects regarding $\mathrm{CHB}$ and $\mathrm{HCC}$, in addition we provide a review of current surveillance guidance and risk stratification models. We reflect on the impact of COVID-19

${ }^{1}$ Faculty of Medicine, UNSW, Sydney, New South Wales, Australia

${ }^{2}$ Barts Liver Centre, Immunobiology, Blizard Institute, Barts and The London School of Medicine \& Dentistry, Queen Mary University of London, London, UK

Correspondence to Dr Patrick T F Kennedy, Immunobiology, Blizard Institute, London E1 2AT, UK; p.kennedy@qmul.ac.uk infection on HCC surveillance and how this crisis could be used as a springboard to determine the timing of initiation of HCC surveillance, by developing novel risk stratification models for $\mathrm{CHB}$ patients in the future.

\section{HEPATITIS B VIRUS}

Chronic hepatitis B virus (HBV) infection is the leading cause of HCC worldwide, with $30 \%$ of the global population showing serological evidence of current or past infection. ${ }^{8}$ It is estimated to result in 780000 deaths per year, the vast majority of which are attributable to cirrhosis and HCC; with cirrhosis being the most important risk factor for HCC development. ${ }^{9} 10$ Universal vaccination programmes for HBV prophylaxis have been successfully adopted in many countries, resulting in reduced mortality. ${ }^{11} 12$ Furthermore, potent antiviral therapy has also significantly impacted HBV outcomes and nucleos(t)ide analogue (NA) therapy has been reported to lower HCC incidence. ${ }^{1314}$ Patients exposed to HBV perinatally or in early childhood are typically characterised by high level HBV DNA in the absence of significant liver injury. ${ }^{15}$ This initial disease phase was previously referred to as 'immune tolerant', but concerns have been raised regarding HBV DNA integration and clonal hepatocyte expansion, events associated with hepatocarcinogenesis. A change in the nomenclature in the 2017 European Association for the Study of Liver (EASL) guidelines to 'e-Antigen positive chronic infection', underscored the possibility of disease progression and the risk of HCC development during this disease phase. ${ }^{16}$ The emergence of a subsequent immune response with perturbation in liver enzymes and reduction in HBV DNA, leads to the 'immune clearance' phase (e-Antigen positive chronic hepatitis). ${ }^{17} 18$ An integral event is hepatitis B e antigen $(\mathrm{HBeAg})$ seroconversion and importantly, patients achieving this before the age of 30 are recognised to have a lower chance of progression to cirrhosis and HCC. ${ }^{19}$ The majority of individuals become 'inactive carriers' after spontaneous $\mathrm{HBeAg}$ seroconversion, defined as the 'e-Antigen negative chronic infection' phase, which is associated with a lower risk of progression to cirrhosis and HCC. ${ }^{20}$ Conversely, reactivation due to the presence of core and pre-core mutants can lead to elevated HBV DNA and alanine aminotransferase (ALT) causing disease progression and HCC development. Thus, disease phase along with other recognised patient factors such as age, ethnicity and family history of HCC govern the timing of HCC surveillance.

\section{HEPATOCELLULAR CARCINOMA}

HCC is the third-leading cause of cancerrelated death worldwide with the highest incidence in Africa and Asia. ${ }^{21}$ The majority of HCC cases arise in the context of underlying cirrhosis, with incremental effect of risk factors such as hepatotropic viruses, alcohol misuse and the metabolic syndrome, ${ }^{22}$ but importantly $\mathrm{HBV}$ is an oncogenic virus, thus HCC can occur in the absence of advanced liver damage or cirrhosis.

An important component of hepatocellular carcinogenesis is HBV DNA integration, which preferentially occurs at sites of double-stranded breaks in genomic DNA. ${ }^{23} \mathrm{HBV} \mathrm{X}$ protein is a functionally active component of integrated HBV DNA that promotes cell cycle progression, silences tumour suppressor genes and instigates chromosomal instability. ${ }^{24}$ HBV DNA integration can be used as a marker of expanding hepatocyte lineages, which can promote a HBV resistant state in response to persistent immune killing of infected hepatocytes. ${ }^{25}$ Importantly, we and others have shown that events such as HBV DNA integration and clonal hepatocyte expansion are already present in patients in the early phase of disease, ${ }^{26} 27$ and this is a key tenet to the development of HCC in non-cirrhotic individuals with $\mathrm{CHB}$ infection. It is, therefore, critical to consider these molecular dynamics of HBV for HCC surveillance. Separate meta-analyses demonstrate that specific $\mathrm{HBV}$ mutations ${ }^{28}$ and genotype $\mathrm{C}$ infection $^{29}$ are associated with an increased risk of HCC. Non-modifiable host factors as previously mentioned; older age and male sex; have consistently been validated as independent risk factors for HCC and included in various HCC risk scores, discussed further in this review. Other risk factors for HCC development include excessive alcohol intake, ${ }^{30}$ aflatoxin exposure ${ }^{31}$ coinfection with hepatitis $\mathrm{D}$ virus (HDV), HIV 32 and now increasingly recognised, the metabolic syndrome. ${ }^{34}$ In 


\begin{tabular}{|c|c|c|c|}
\hline & EASL (2017) & AASLD (2018) & APASL (2015) \\
\hline Who? & $\begin{array}{l}\text { Suggests consideration of host and disease factors } \\
\text { Suggests risk scores (eg, PAGE-B) to stratify } \\
\text { patients as low, moderate or high risk } \\
\text { Recommends surveillance for patients: } \\
\text { - Undergoing long-term NA therapy } \\
\text { - With cirrhosis } \\
\text { - With moderate/high risk at onset of NA therapy } \\
\text { - Recommends against surveillance for patients: } \\
\text { - With low risk }\end{array}$ & $\begin{array}{l}\text { Recommends surveillance for } \mathrm{HBs} A g+\text { patients } \\
\text { with: } \\
\text { - Cirrhosis } \\
\text { - High risk (Asian/Black men }>40 \text { years, } \\
\text { - Asian women }>50 \text { years) } \\
\text { - History of } \mathrm{HCC} \text { in first degree relative } \\
\text { - } \text { HDV coinfection }\end{array}$ & $\begin{array}{l}\text { Affirms risk prediction scores can accurately risk } \\
\text { stratify patients } \\
\text { Suggests threshold incidence of surveillance be } \\
\text { determined individually based on the economic } \\
\text { situation of each country } \\
\text { Recommends surveillance for patients with: } \\
\text { - CHB at high risk } \\
\text { Recommends against surveillance for patients with: } \\
\text { - Class C Child-Pugh scores. }\end{array}$ \\
\hline How? & Not stated & $\begin{array}{l}\text { Recommends ultrasound } \pm \text { AFP } 6 \text { monthly } \\
\text { States insufficient evidence for/against } \\
\text { inclusion of AFP in screening algorithms }\end{array}$ & $\begin{array}{l}\text { Recommends USS+AFP } 6 \text { monthly, or preferably } 3 \\
\text { monthly in cirrhotics and those at high risk } \\
\text { Recommends contrast-CT or contrast-MRI to confirm } \\
\text { suspicious ultrasound lesions AND for initial screening } \\
\text { of patients with advanced cirrhosis and high suspicion } \\
\text { of HCC development } \\
\text { Recommends baseline contrast-CT or contrast-MRI } \\
\text { obtained in all cirrhotics at presentation }\end{array}$ \\
\hline
\end{tabular}

AASLD, American Association for the Study of Liver Diseases; AFP, alpha fetoprotein; APASL, Asian Pacific Association for the Study of the Liver; CHB, chronic hepatitis B; EASL, European Association for the Study of the Liver; HBsAg+, hepatitis B surface antigen positive; HBV, hepatitis B virus; HCC, hepatocellular carcinoma; HDV, hepatitis D virus; NA, nucleos(t)ide analogue.

a 2015 case-control study, evidence of the metabolic syndrome (presence of diabetes, obesity in early adulthood) increased the OR for HCC development by sixfold. Although the OR for the development of HCC in CHB patients is $30-40,{ }^{35}$ it is not proven whether the presence of $\mathrm{CHB}$ in conjunction with the metabolic syndrome leads to a synergistic effect on HCC development. A recent study reported that patients with $\mathrm{CHB}$ and liver steatosis had a greater mortality and risk of developing HCC compared with CHB patients without steatosis. ${ }^{36}$ Thus, the metabolic syndrome is emerging as an important coaetiology with $\mathrm{CHB}$ when evaluating HCC risk.

\section{HCC SURVEILLANCE GUIDELINES}

Advances in the understanding and treatment of HBV necessitate regular updating of HCC surveillance guidelines. Evaluation of international guidelines, (table 1), reveal discrepancies between the specified populations at risk. While all guidelines agree that the presence of cirrhosis mandates regular surveillance, they differ in how they broadly stratify the ever changing concept of HCC risk. The EASL guidelines $^{37}$ identify, but fall short of recommending conventional risk scores, each of which is based on a varying combination of host and viral factors. These risk scores are affirmed in the Asian Pacific Association for the Study of the Liver (APASL) guidelines, ${ }^{38}$ aligning with the fact that most are validated in Asian populations, but are omitted from the American Association for the Study of Liver Diseases (AASLD) guidelines. ${ }^{39}$ There is broad agreement, however, across the liver disease organisations on the use of abdominal ultrasound scan (USS) every 6 months as the appropriate method of HCC surveillance. The AASLD and APASL guidelines differ on their recommendation of using serum AFP for risk assessment, as studies have demonstrated the lack of sensitivity and specificity of AFP in diagnosing HCC. ${ }^{40}{ }^{41}$ Importantly, during the COVID-19 pandemic, there is acceptance in the field that HCC surveillance can be deferred, ${ }^{6} 7$ thus, both healthcare professionals and patients will have to accept delays in access to liver imaging in the short term. However, there is an onus on specialists to provide an exit strategy to this disruption, or put simply, provide a cogent way forward to prioritise those at greatest need for HCC surveillance.

\section{HCC RISK SCORES}

In the current COVID-19 era of reducing or potentially delaying HCC surveillance, the use of risk scores in $\mathrm{CHB}$ patients may enhance stratification, which could be integrated in future practice to prevent unnecessary tests. The early risk stratification scores, including Guide with age, gender, HBV DNA, core promoter mutations and cirrhosis (-HCC, ${ }^{42}$ cumulative HCC (CU-HCC) ${ }^{43}$ and Risk Estimation for Hepatocellular Carcinoma in Chronic Hepatitis B (REACH-B), ${ }^{44}$ consider patient demographics and disease-related factors. All three conventional risk scores include HBV DNA; where a high HBV DNA was thought to directly correlate with HCC development, despite HBV being a noncytopathic virus. ${ }^{45}$ Conversely, recent data have shown that HBV DNA is not independently associated with HCC occurrence in patients treated with NA therapy, ${ }^{46} 47$ justifying its exclusion in newer risk scores. Indeed, more recent studies suggest the incorporation of HBV DNA may reduce the predictive capacity of these models, as the natural history of $\mathrm{CHB}$ has evolved in the era of widespread antiviral uptake. ${ }^{48}$

The discriminatory performance of these three risk scores in Caucasian patients has been limited, ${ }^{49} 50$ possibly due to differences in genotype distribution. In contrast, the PAGE-B score (based on patients' age, gender and platelets) was modelled around a treated Caucasian cohort, ${ }^{51}$ and has since been validated in treated Asian patients, showing similar or superior predictive performance to the GAG-HCC and CU-HCC risk scores. ${ }^{52} \mathrm{~A}$ modified PAGE-B (mPAGE-B) score has been developed in a treated Asian cohort, where serum albumin as an independent predictor of HCC development prompted its inclusion as a factor in the risk model. ${ }^{53}$ The mPAGE-B score demonstrated better predictive performance than the original PAGE-B score and other conventional risk models in the original study, ${ }^{53}$ but an external validation study has demonstrated similar performance compared with the original PAGE-B score. ${ }^{54}$

While hepatic fibrosis, and specifically cirrhosis, is the single most important risk factor for HCC, 55 the invasive nature of liver biopsy has precluded its inclusion in older HCC risk models. However the adoption of transient elastography (TE) allows for accurate and non-invasive means of liver stiffness measurement (LSM). TE has now been included in the development of new risk scores, ${ }^{56}$ as well as the 
Table 2 Details of contemporary HCC risk scores

\begin{tabular}{|c|c|c|c|}
\hline Risk score & Components & Original cohort & Validation (V)/performance (P) \\
\hline LSM-Based Model $(2013)^{56}$ & $\begin{array}{l}\text { Age } \\
\text { Gender } \\
\text { HBV DNA } \\
\text { LSM }\end{array}$ & - Asian cohort (mixed treatment status) & V; none in other cohorts \\
\hline LSM-HCC $(2014)^{57}$ & $\begin{array}{l}\text { Age } \\
\text { Albumin } \\
\text { HBV DNA } \\
\text { LSM }\end{array}$ & - Asian cohort (mixed treatment status) & $\begin{array}{l}\text { Modification of CU-HCC: } \\
\text { V: Asian cohorts (mixed treatment status) })^{5960} \\
\text { P: superior to conventional risk scores and PAGE } \mathrm{B}^{60} \\
\text { similar to mREACH-B } \mathrm{B}^{59} 60\end{array}$ \\
\hline mREACH-B $(2014)^{58}$ & $\begin{array}{l}\text { Age } \\
\text { Gender } \\
\text { ALT } \\
\text { HBeAg status } \\
\text { LSM }\end{array}$ & - Treated Asian cohort & $\begin{array}{l}\text { Modification of REACH-B: } \\
\text { V: Asian cohorts (mixed treatment status) })^{485960} \\
\text { P: superior to conventional risk scores }{ }^{455} \text { and } \\
\text { contemporary risk scores }{ }^{5960}\end{array}$ \\
\hline PAGE-B (2016) $)^{51}$ & $\begin{array}{l}\text { Age } \\
\text { Gender } \\
\text { Platelets }\end{array}$ & - Treated Caucasian cohort & $\begin{array}{l}\text { V: treated Asian cohorts }{ }^{525460} \\
\text { P: similar or superior to conventional risk scores, } \\
\text { similar to mPAGE-B } \\
\text { mREACH-B }{ }^{50} \text { but inferior to LSM-HCC and }\end{array}$ \\
\hline mPAGE-B $(2018)^{53}$ & $\begin{array}{l}\text { Age } \\
\text { Gender } \\
\text { Platelets } \\
\text { Albumin }\end{array}$ & - Treated Asian cohort & $\begin{array}{l}\text { Modification of PAGE-B: } \\
\text { V: treated Asian cohort } \\
\text { P: similar or superior to conventional risk scores }{ }^{54}\end{array}$ \\
\hline
\end{tabular}

ALT, alanine aminotransferase; CU-HCC, cumulative HCC; HBeAg, hepatitis B e antigen; HBV, hepatitis B virus; HCC, hepatocellular carcinoma; LSM, liver stiffness measurement; mPAGE-B, modified PAGE-B.

modification of old scoring systems, ${ }^{57} 58$ these contemporary risk scores have been outlined in table 2. While the LSM-Based Model uses LSM as a continuous variable, the LSM-HCC and modified REACH-B (mREACH-B) models use discrete cut-offs to stratify patients into three categories for simpler scoring. The LSM-HCC model modifies the CU-HCC score by replacing USS as a surrogate measure of cirrhosis with LSM, while the mREACH-B score substitutes HBV DNA with LSM. Both of these modified risk scores yield better predictive performance than their original models. ${ }^{57}{ }^{58}$ In external validation studies, the LSM-HCC and mREACH-B scores demonstrate superior performance in comparison to conventional risk scores, as well as the PAGE-B score, which are best used in patients established on antiviral therapy regardless of $\mathrm{HBeAg}$ status. ${ }^{59} 60$ Thus, in the current COVID-19 pandemic where healthcare professionals managing $\mathrm{CHB}$ patients are requested to delay standard USS imaging, such modified risk scores could easily be used to better stratify the need for HCC surveillance in patients. Cut-off scores for the PAGE-B model are specified, but this is not the case for the mREACH-B score, however, the validation study for this model did propose thresholds. Utilising these cut-off scores allows for the improved interpretation of these models to determine the timing of HCC surveillance; these are summarised in table 3. The cut-offs provided for both risk models are in accordance with the reported 5-year CU-HCC incidence rates, approximately $0 \%$ for low risk, 3\%-4\% for intermediate risk and $>10 \%$ for high risk. Thus, using these scores, with their designated thresholds would lead to more robust identification of 'at-risk' patients for earlier HCC surveillance, when healthcare services return to standard activity in due course.

\section{QUANTITATIVE HEPATITIS B SURFACE ANTIGEN AND HEPATITIS B CORE-RELATED ANTIGEN AS NEW BIOMARKERS FOR HCC RISK}

HBV DNA in the context of antiviral therapy is less discriminatory and this has been reflected in the evolution of HCC risk scores. This heralds the potential role of new biomarkers such as quantitative hepatitis B surface antigen (qHBsAg) and hepatitis B core-related antigen ( $\mathrm{HBcrAg}$ ) levels, which may also inform HCC risk. $\mathrm{HBsAg}$ levels vary over the natural course of CHB and typically decrease over time, as patients progress to e-Antigen negative chronic infection, ${ }^{61}$ while late-stage elevation of HBsAg levels may reflect the development of e-Antigen negative chronic hepatitis or HBV DNA integration.

The recently published SONIC-B study has pooled data from eight global randomised trials to support the hypothesis that HBsAg levels inversely correlate with severity of fibrosis and cirrhosis in HBeAg positive patients. ${ }^{62}$ This aligns with previous, smaller-scale natural history studies, ${ }^{63} 64$ demonstrating the clinical utility of HBsAg cut-offs to rule out cirrhosis. These findings support the hypothesis that lower serum HBsAg levels imply longer durations of HBV-related hepatic inflammation, and are in keeping with evidence that longer duration of HBsAg exposure leads to attrition of virus-specific T cell responses. ${ }^{65}$

However, it is noteworthy that HCC risk has been shown to be significantly reduced in $\mathrm{HBeAg}$ negative patients who achieve HBsAg seroclearance, either

Table 3 Interpretation of recommended risk scores

\begin{tabular}{llll}
\hline Risk score & Score & Risk interpretation & Recommendation \\
\hline mREACH- $^{58}$ & $\leq 5$ & Low risk & HCC surveillance not recommended \\
& $6-7$ & Low-intermediate risk & HCC surveillance recommended \\
& $8-10$ & High-intermediate risk & HCC surveillance recommended \\
& $\geq 11$ & High risk & HCC surveillance strongly recommended \\
PAGE-B ${ }^{51}$ & $\leq 9$ & Low risk & HCC surveillance not recommended \\
& $10-17$ & Medium risk & HCC surveillance recommended \\
& $\geq 18$ & High risk & HCC surveillance strongly recommended \\
\hline
\end{tabular}

$\mathrm{HCC}$, hepatocellular carcinoma. 
spontaneously ${ }^{66} 67$ or with antiviral therapy. ${ }^{6869}$ Studies have shown that HBsAg levels are independently associated with the development of cirrhosis and HCC in patients with low levels of HBV DNA. ${ }^{70} 71$ A positive correlation between HBsAg level and HCC has also been reported in patients with intermediate (grey-zone) viral load, defined as HBV DNA 2000-20 000IU/ $\mathrm{mL},{ }^{72}$ although the timing of $\mathrm{qHBsAg}$ measurement is vital to its interpretation and utility.

While qHBsAg proves an important marker in monitoring disease progression and/or treatment response in patients with low level viraemia, there is a need to validate a safe HBsAg cut-off level as a threshold for HCC surveillance. Taiwanese data demonstrated that higher HBsAg levels correlated with HCC risk particularly in e-Antigen negative patients with HBV DNA $<2000 \mathrm{IU} / \mathrm{mL}$. The authors proposed a HBsAg threshold of $1000 \mathrm{IU} / \mathrm{mL}$ to delineate HCC risk, with an adjusted HR for HCC development of 13.7 (95\% CI 4.8 to 39.3 ) in their cohort of treatment-naïve patients. ${ }^{70}$ Newly proposed algorithms have used this threshold to complement HCC risk stratification in e-Antigen negative patients with HBV DNA <2000 IU/mL and normal ALT levels. ${ }^{73}$ Additionally, the incorporation of HBsAg levels into a HCC risk score modelled off data from the REVEAL-HBV study has demonstrated exceptional prediction accuracy and discriminatory ability for 5-year, 10-year and 15-year HCC risk. In this analysis, $\mathrm{CHB}$ patients demonstrated multivariate-adjusted HRs for HCC development of 2.83 (1.555.18) and $4.06(2.24-7.36)$ for patient groups with HBsAg levels 100-900 and $>1000 \mathrm{IU} / \mathrm{mL}$ respectively, in comparison to those with HBsAg level $<100 \mathrm{IU} / \mathrm{mL}{ }^{71}$

$\mathrm{HBcrAg}$, combining antigenic reactivity resulting from $\mathrm{HBcAg}$, denatured $\mathrm{HBeAg}$ and artificial core-related protein $\mathrm{p} 22 \mathrm{cr}$ has been found to correlate well with serum HBV DNA until the initiation of antiviral therapy, at which point $\mathrm{HBcrAg}$ declines at a slower rate than HBV DNA. ${ }^{74}$ As such, it can be regarded as a marker for persistence of HBV, and has been found to significantly correlate with intrahepatic cccDNA in liver biopsy studies. ${ }^{75-77} \mathrm{HBcrAg}$ levels have been found to independently predict hepatocarcinogenesis in untreated patients, ${ }^{78}{ }^{79}$ as well as patients receiving NAs. ${ }^{80-82}$ In fact, it may be superior to HBsAg in predicting HCC risk in treated patients with undetectable HBV DNA, ${ }^{83}$ underlining its potential utility in the future.

To our knowledge, there are no published risk models that incorporate $\mathrm{HBcrAg}$ levels,
Table 4 Coaetiologies, molecular events and novel parameters for individual HCC risk assessment

\begin{tabular}{|c|c|}
\hline $\begin{array}{l}\text { Future research directions } \\
\text { in assessing HCC risk }\end{array}$ & $\begin{array}{l}\text { Examples of } \\
\text { parameters }\end{array}$ \\
\hline \multirow{3}{*}{$\begin{array}{l}\text { Incorporating new viral } \\
\text { factors }\end{array}$} & Specific HBV mutations \\
\hline & HBV genotype* \\
\hline & HBV DNA integration \\
\hline \multirow{5}{*}{$\begin{array}{l}\text { Incorporating new host } \\
\text { factors }\end{array}$} & Metabolic syndrome \\
\hline & $\begin{array}{l}\text { Excessive alcohol } \\
\text { intake }\end{array}$ \\
\hline & HDV or HIV coinfection \\
\hline & $\begin{array}{l}\text { Other hepatic co- } \\
\text { aetiologies }\end{array}$ \\
\hline & Treatment status $\dagger$ \\
\hline \multirow{2}{*}{$\begin{array}{l}\text { Incorporating new } \\
\text { quantitative biomarkers }\end{array}$} & qHBsAg \\
\hline & $\mathrm{HBcrAg}$ \\
\hline
\end{tabular}

*Inclusion of all HBV genotypes.

tInclusion of patients regardless of treatment (naïve and experienced patients).

$\mathrm{HBCrAg}$, hepatitis B core-related antigen; HBV, hepatitis B virus; HCC, hepatocellular carcinoma; HDV, hepatitis D virus; qHBsAg, quantitative hepatitis $B$ surface antigen.

nor is there a consensus on a safe HBcrAg cut-off level to help inform the decision of whether to initiate HCC surveillance. Correspondingly, any existing or upcoming risk models that incorporate $\mathrm{HBcrAg}$ levels require validation in cohorts of patients with different demographics including gender, age, ethnicity, viral genotype and treatment status. The design of future studies should align with these goals in order to increase the relevance of HBcrAg and $\mathrm{qHBsAg}$ for practising clinicians. Indeed, viral and host factors, such as metabolic syndrome, alcohol intake and coinfection, are not included in current risk scores, but should be part of future risk stratification. Importantly, future research will have to address the utility of novel viral markers, molecular events associated with HBV DNA integration and host factors in determining HCC risk prior to their incorporation and validation in new models. We have outlined these various factors, which could be used to improve HCC risk scores in the future (table 4). The advent of novel risk scores and models incorporating these parameters, along with those already included in validated scores, may further improve risk stratification for HCC surveillance, which could be adopted to determine the optimal timing for the initiation of HCC surveillance in a personalised way in the future.

\section{A WAY FORWARD \\ Prioritisation during COVID-19}

The COVID-19 crisis has brought great disruption to healthcare systems across the world, significantly impacting established care pathways and planned patient activity, in order to meet the challenge of the global pandemic. Regrettably, HCC surveillance programmes along with many other cancer screening programmes have been and will continue to be disrupted as a consequence of this public health emergency for some time. In these challenging times, it is imperative that we adapt clinical practice in a timely way to maintain the highest standards of patient care and safety. During the COVID-19 crisis, we propose a strategy to streamline $\mathrm{HCC}$ surveillance, a preventative programme, which is critical to the long-term health of at-risk $\mathrm{CHB}$ patients. In light of the current urgency, we suggest that clinicians commit to using contemporary HCC risk scores to inform the risk stratification of their $\mathrm{CHB}$ patients. We recommend the mREACH-B score as the preferred risk model for $\mathrm{CHB}$ patients currently taking or maintained on antiviral therapy. In the absence of the availability of a LSM reading, which is likely to be the case in less economically developed countries, we recommend the PAGE-B score. Using the cut-off scores, as outlined in table 3 , patients who require more urgent HCC surveillance can be identified and prioritised.

\section{Development of future risk scores}

Moving forward clinicians and healthcare workers involved in the care of $\mathrm{CHB}$ patients should learn the 'lessons' from the COVID-19 crisis to improve future HCC surveillance. Initially, by adopting the contemporary HCC risk models with their established cut-off scores for prioritisation, the timing and initiation of HCC surveillance could be enhanced. We envisage that HCC risk scores will be improved further by the inclusion of the additional factors outlined in table 4. Future research will have to evaluate the effect of host risk factors in HCC development; including the presence of the metabolic syndrome, alcohol use and coinfection; which are currently not accounted for in the development of risk scores. Additionally, levels of $\mathrm{HBsAg}$ and $\mathrm{HBcrAg}$ may be of value in assessing both e-Antigen positive and negative patients, with and without antiviral therapy, and should be incorporated into future HCC risk scores. Critically, it is vital that existing and future risk scores are further confirmed by robust external validation studies in diverse $\mathrm{CHB}$ patient cohorts. While these risk models will be of particular value in the midst of the current pandemic, we believe that they can play an important role to inform the decision and 
timing to initiate HCC surveillance when healthcare systems eventually adapt to a post-COVID era.

Twitter Upkar S Gill @druppygill

Contributors GZ: literature review, drafting of manuscript. USG and PTFK: drafting, editing and critical review of manuscript.

Competing interests GZ and USG have no conflicts of interest to declare; PTFK has collaborative grant funding from Gilead, participates in advisory board/ provides consultancy to Gilead, GSK, Janssen and is an investigator for industry led trials with Abbott, Gilead, Janssen, Roche and Springbank.

Patient and public involvement Patients and/or the public were not involved in the design, or conduct, or reporting, or dissemination plans of this research.

Patient consent for publication Not required.

Provenance and peer review Not commissioned; externally peer reviewed.

Data availability statement There are no data in this work.

\section{(2) OPEN ACCESS}

Open access This is an open access article distributed in accordance with the Creative Commons Attribution 4.0 Unported (CC BY 4.0) license, which permits others to copy, redistribute, remix, transform and build upon this work for any purpose, provided the original work is properly cited, a link to the licence is given, and indication of whether changes were made. See: https:// creativecommons.org/licenses/by/4.0/.

(c) Author(s) (or their employer(s)) 2020. Re-use permitted under CC BY. Published by BMJ.

- Additional material is published online only. To view please visit the journal online (http://dx.doi.org/ 10.1136/gutjnl-2020-321627)

\section{Check for updates}

To cite Zeng G, Gill US, Kennedy PTF. Gut 2020:69:1907-1912.

Received 29 April 2020

Revised 11 May 2020

Accepted 12 May 2020

Published Online First 25 May 2020

Gut 2020;69:1907-1912.

doi:10.1136/gutjnl-2020-321627

ORCID iD

Patrick T F Kennedy http://orcid.org/0000-0001-92010094

\section{REFERENCES}

1 Cucinotta D, Vanelli M. Who Declares COVID-19 a pandemic. Acta Biomed 2020:91:157-60.

2 Huang C, Wang Y, Li X, et al. Clinical features of patients infected with 2019 novel coronavirus in Wuhan, China. Lancet 2020;395:497-506.

3 Remuzzi A, Remuzzi G. COVID-19 and Italy: what next? The Lancet 2020;395:1225-8.

4 Yuan J, Li M, Lv G, et al. Monitoring transmissibility and mortality of COVID-19 in Europe. Int I Infect Dis 2020;95:311-5.

5 COVID C, Team R. Severe Outcomes Among Patients with Coronavirus Disease 2019 (COVID-19) - United
States, February 12-March 16, 2020. MMWR Morb Mortal Wkly Rep 2020:69:343-6.

6 Boettler T, Newsome PN, Mondelli MU, et al. Care of patients with liver disease during the COVID-19 pandemic: EASL-ESCMID position paper. JHEP Rep 2020:2:100113

7 AASLD. Clinical insights for hepatology and liver transplant providers during the COVID-19 pandemic, 2020. Available: www.aasld.org

8 Trépo C, Chan HLY, Lok A. Hepatitis B virus infection. Lancet 2014:384:2053-63.

9 Jefferies M, Rauff B, Rashid H, et al. Update on global epidemiology of viral hepatitis and preventive strategies. World I Clin Cases 2018;6:589-99.

10 Hsu HM, Chen DS, Chuang CH, et al. Efficacy of a mass hepatitis B vaccination program in Taiwan. Studies on 3464 infants of hepatitis B surface antigen-carrier mothers. JAMA 1988;260:2231-5.

11 Tsebe KV, Burnett RJ, Hlungwani NP, et al. The first five years of universal hepatitis $B$ vaccination in South Africa: evidence for elimination of $\mathrm{HBs} A g$ carriage in under 5-year-olds. Vaccine 2001;19:3919-26.

12 Chaouch H, Taffon S, Villano U, et al. Naturally occurring surface antigen variants of hepatitis $B$ virus in Tunisian patients. Intervirology 2016;59:36-47.

13 Marcellin P, Gane E, Buti M, et al. Regression of cirrhosis during treatment with tenofovir disoproxil fumarate for chronic hepatitis B: a 5-year open-label follow-up study. Lancet 2013;381:468-75.

14 Papatheodoridis GV, Chan HL-Y, Hansen BE, et al. Risk of hepatocellular carcinoma in chronic hepatitis $B$ : assessment and modification with current antiviral therapy. J Hepatol 2015;62:956-67.

15 Andreani T, Serfaty L, Mohand D, et al. Chronic hepatitis $B$ virus carriers in the immunotolerant phase of infection: histologic findings and outcome. Clin Gastroenterol Hepatol 2007:5:636-41.

16 European Association for the Study of the Liver. Electronic address: easloffice@easloffice.eu, European Association for the Study of the Liver. EASL 2017 clinical practice guidelines on the management of hepatitis B virus infection. J Hepatol 2017;67:370-98.

17 Fattovich G, Bortolotti F, Donato F. Natural history of chronic hepatitis B: special emphasis on disease progression and prognostic factors. J Hepatol 2008:48:335-52.

18 Shi Y-H, Shi C-H. Molecular characteristics and stages of chronic hepatitis B virus infection. World J Gastroenterol 2009;15:3099-105

19 Chen Y-C, Chu C-M, Liaw Y-F. Age-Specific prognosis following spontaneous hepatitis $B$ e antigen seroconversion in chronic hepatitis B. Hepatology 2010:51:435-44

20 Sharma SK, Saini N, Chwla Y. Hepatitis B virus: inactive carriers. Virol J 2005:2:82.

21 Singal AG, El-Serag HB. Hepatocellular carcinoma from epidemiology to prevention: translating knowledge into practice. Clin Gastroenterol Hepatol 2015:13:2140-51.

22 Ghouri YA, Mian I, Rowe JH. Review of hepatocellular carcinoma: epidemiology, etiology, and carcinogenesis. J Carcinog 2017;16:1.

23 Bill CA, Summers J. Genomic DNA double-strand breaks are targets for hepadnaviral DNA integration. Proc Natl Acad Sci U S A 2004;101:11135-40.

24 Kew MC. Hepatitis $B$ virus $X$ protein in the pathogenesis of hepatitis $B$ virus-induced hepatocellular carcinoma. J Gastroenterol Hepatol 2011;26 Suppl 1:144-52.

25 Mason WS, Liu C, Aldrich CE, et al. Clonal expansion of normal-appearing human hepatocytes during chronic hepatitis B virus infection. J Virol 2010;84:8308-15.

26 Mason WS, Gill US, Litwin S, et al. Hbv DNA integration and clonal hepatocyte expansion in chronic hepatitis B patients considered immune tolerant. Gastroenterology 2016;151:986-98.

27 Tu T, Mason WS, Clouston AD, et al. Clonal expansion of hepatocytes with a selective advantage occurs during all stages of chronic hepatitis B virus infection. $J$ Viral Hepat 2015:22:737-53.

28 Liu S, Zhang H, Gu C, et al. Associations between hepatitis $B$ virus mutations and the risk of hepatocellular carcinoma: a meta-analysis. J Natl Cancer Inst 2009:101:1066-82.

29 Wong GL-H, Chan HL-Y, Yiu KK-L, et al. Meta-Analysis: the association of hepatitis $B$ virus genotypes and hepatocellular carcinoma. Aliment Pharmacol Ther 2013;37:517-26

30 Donato F, Tagger A, Gelatti U, et al. Alcohol and hepatocellular carcinoma: the effect of lifetime intake and hepatitis virus infections in men and women. Am J Epidemiol 2002;155:323-31.

31 Waly Raphael S, Yangde Z, Yuxiang C. Hepatocellular carcinoma: focus on different aspects of management. ISRN Oncol 2012:2012:421673

32 Fattovich G, Giustina G, Christensen E, et al. Influence of hepatitis delta virus infection on morbidity and mortality in compensated cirrhosis type B. The European concerted action on viral hepatitis (Eurohep). Gut 2000:46:420-6.

33 Bonacini $\mathrm{M}$, Louie $\mathrm{S}$, Bzowej $\mathrm{N}$, et al. Survival in patients with HIV infection and viral hepatitis B or C: a cohort study. AIDS 2004;18:2039-45.

34 Wong GL-H, Wong VW-S, Choi PC-L, et al. Metabolic syndrome increases the risk of liver cirrhosis in chronic hepatitis B. Gut 2009:58:111-7.

35 Gerbes A, Zoulim F, Tilg H, et al. Gut roundtable meeting paper: selected recent advances in hepatocellular carcinoma. Gut 2018;67:380-8.

36 Peleg N, Issachar A, Sneh Arbib O, et al. Liver steatosis is a strong predictor of mortality and cancer in chronic hepatitis B regardless of viral load. JHEP Rep 2019:1:9-16.

37 European Association for the Study of the Liver. Electronic address: easloffice@easloffice.eu, European Association for the Study of the LiverLampertico P, Agarwal K, Berg T. EASL 2017 clinical practice guidelines on the management of hepatitis $B$ virus infection. J Hepatol 2017:67:370-98.

38 Sarin SK, Kumar M, Lau GK, et al. Asian-Pacific clinical practice guidelines on the management of hepatitis $B$ : 2015 update. Hepatol Int 2016:10:1-98.

39 Terrault NA, Lok ASF, McMahon BJ, et al. Update on prevention, diagnosis, and treatment of chronic hepatitis B: AASLD 2018 hepatitis B guidance. Hepatology 2018:67:1560-99.

40 Lok AS, Sterling RK, Everhart JE, et al. Des-GammaCarboxy prothrombin and alpha-fetoprotein as biomarkers for the early detection of hepatocellular carcinoma. Gastroenterology 2010;138:493-502.

41 Singal A, Volk ML, Waljee A, et al. Meta-Analysis: surveillance with ultrasound for early-stage hepatocellular carcinoma in patients with cirrhosis. Aliment Pharmacol Ther 2009;30:37-47.

42 Yuen M-F, Tanaka Y, Fong DY-T, et al. Independent risk factors and predictive score for the development of hepatocellular carcinoma in chronic hepatitis B. J Hepatol 2009;50:80-8.

43 Wong VW-S, Chan SL, Mo F, et al. Clinical scoring system to predict hepatocellular carcinoma in chronic hepatitis B carriers. J Clin Oncol 2010;28:1660-5.

44 Yang H-I, Yuen M-F, Chan HL-Y, et al. Risk estimation for hepatocellular carcinoma in chronic hepatitis B (REACH-B): development and validation of a predictive score. Lancet Oncol 2011;12:568-74.

45 Chen C-J, Yang H-I, Su J, et al. Risk of hepatocellular carcinoma across a biological gradient of serum hepatitis B virus DNA level. JAMA 2006;295:65-73.

46 Cho J-Y, Paik Y-H, Sohn W, et al. Patients with chronic hepatitis B treated with oral antiviral therapy retain a higher risk for HCC compared with patients with inactive stage disease. Gut 2014;63:1943-50.

47 Hsu Y-C, Wu C-Y, Lane H-Y, et al. Determinants of hepatocellular carcinoma in cirrhotic patients treated with nucleos(t)ide analogues for chronic hepatitis B. J Antimicrob Chemother 2014;69:1920-7. 
48 Jung KS, Kim SU, Song K, et al. Validation of hepatitis $B$ virus-related hepatocellular carcinoma prediction models in the era of antiviral therapy. Hepatology 2015:62:1757-66.

49 Arends P, Sonneveld MJ, Zoutendijk R, et al. Entecavir treatment does not eliminate the risk of hepatocellular carcinoma in chronic hepatitis $\mathrm{B}$ : limited role for risk scores in Caucasians. Gut 2015;64:1289-95.

50 Papatheodoridis GV, Dalekos GN, Yurdaydin C, et al. Incidence and predictors of hepatocellular carcinoma in Caucasian chronic hepatitis B patients receiving entecavir or tenofovir. J Hepatol 2015;62:363-70.

51 Papatheodoridis G, Dalekos G, Sypsa V, et al. PAGE-B predicts the risk of developing hepatocellular carcinoma in Caucasians with chronic hepatitis B on 5-year antiviral therapy. J Hepatol 2016;64:800-6.

52 Kim MN, Hwang SG, Rim KS, et al. Validation of PAGE-B model in Asian chronic hepatitis B patients receiving entecavir or tenofovir. Liver Int 2017;37:1788-95.

53 Kim JH, Kim YD, Lee M, et al. Modified PAGE-B score predicts the risk of hepatocellular carcinoma in Asians with chronic hepatitis B on antiviral therapy. J Hepatol 2018;69:1066-73.

54 Lee HW, Kim SU, Park JY, et al. External validation of the modified PAGE-B score in Asian chronic hepatitis $\mathrm{B}$ patients receiving antiviral therapy. Liver Int 2019;39:1624-30.

55 Jung KS, Kim SU, Ahn SH, et al. Risk assessment of hepatitis B virus-related hepatocellular carcinoma development using liver stiffness measurement (FibroScan). Hepatology 2011;53:885-94.

56 Kim DY, Song KJ, Kim SU, et al. Transient elastographybased risk estimation of hepatitis B virus-related occurrence of hepatocellular carcinoma: development and validation of a predictive model. Onco Targets Ther 2013:6:1463-9.

57 Wong GL-H, Chan HL-Y, Wong CK-Y, et al. Liver stiffness-based optimization of hepatocellular carcinoma risk score in patients with chronic hepatitis B. J Hepatol 2014;60:339-45.

58 Lee HW, Yoo EJ, Kim BK, et al. Prediction of development of liver-related events by transient elastography in hepatitis B patients with complete virological response on antiviral therapy. $A m \mathrm{~J}$ Gastroenterol 2014;109:1241-9.

$59 \mathrm{Kim}$ MN, Kim SU, Kim BK, et al. Increased risk of hepatocellular carcinoma in chronic hepatitis $B$ patients with transient elastography-defined subclinical cirrhosis. Hepatology 2015;61:1851-9.

60 Seo YS, Jang BK, Um SH, et al. Validation of risk prediction models for the development of HBV-related
HCC: a retrospective multi-center 10-year follow-up cohort study. Oncotarget 2017;8:113213-24.

61 Jaroszewicz J, Calle Serrano B, Wursthorn K, et al. Hepatitis B surface antigen ( $\mathrm{HBsAg}$ ) levels in the natural history of hepatitis B virus (HBV)-infection: a European perspective. J Hepatol 2010;52:514-22.

62 Sonneveld MJ, Hansen BE, Brouwer WP, et al. Hbsag levels can be used to rule out cirrhosis in $\mathrm{HBeAg}$ positive chronic hepatitis $B$ : results from the sonic-b study. J Infect Dis 2020. doi:10.1093/infdis/jiaa192. [Epub ahead of print: $21 \mathrm{Apr}$ 2020].

63 Martinot-Peignoux M, Carvalho-Filho R, Lapalus $M$, et al. Hepatitis B surface antigen serum level is associated with fibrosis severity in treatment-naive, $\mathrm{E}$ antigen-positive patients. J Hepatol 2013;58:1089-95.

64 Goyal SK, Jain AK, Dixit VK, et al. Hbsag level as predictor of liver fibrosis in $\mathrm{HBeAg}$ positive patients with chronic hepatitis B virus infection. J Clin Exp Hepatol 2015;5:213-20.

65 Le Bert N, Gill US, Hong M, et al. Effects of hepatitis B surface antigen on virus-specific and global T cells in patients with chronic HBV infection. Gastroenterology 2020. doi:10.1053/j.gastro.2020.04.019. [Epub ahead of print: 14 Apr 2020].

66 Simonetti J, Bulkow L, McMahon BJ, et al. Clearance of hepatitis B surface antigen and risk of hepatocellular carcinoma in a cohort chronically infected with hepatitis B virus. Hepatology 2010;51:1531-7.

67 Liu J, Yang H-I, Lee M-H, et al. Spontaneous seroclearance of hepatitis B seromarkers and subsequent risk of hepatocellular carcinoma. Gut 2014;63:1648-57.

68 Kim G-A, Lim Y-S, An J, et al. Hbsag seroclearance after nucleoside analogue therapy in patients with chronic hepatitis B: clinical outcomes and durability. Gut 2014;63:1325-32

69 Yip TC-F, Wong GL-H, Chan HL-Y, et al. HBsAg seroclearance further reduces hepatocellular carcinoma risk after complete viral suppression with nucleos(t)ide analogues. J Hepatol 2019;70:361-70.

70 Tseng T-C, Liu C-J, Yang H-C, et al. High levels of hepatitis $B$ surface antigen increase risk of hepatocellular carcinoma in patients with low HBV load. Gastroenterology 2012;142:e3:1140-9.

71 Lee M-H, Yang H-I, Liu J, et al. Prediction models of long-term cirrhosis and hepatocellular carcinoma risk in chronic hepatitis B patients: risk scores integrating host and virus profiles. Hepatology 2013;58:546-54.

72 Tseng T-C, Liu C-J, Chen C-L, et al. Risk stratification of hepatocellular carcinoma in hepatitis $B$ virus E antigen-negative carriers by combining viral biomarkers. J Infect Dis 2013:208:584-93.
$73 \mathrm{Kao} \mathrm{J}-\mathrm{H}$. Risk stratification of HBV infection in AsiaPacific region. Clin Mol Hepatol 2014;20:223-7.

74 Rokuhara A, Tanaka E, Matsumoto A, et al. Clinical evaluation of a new enzyme immunoassay for hepatitis $B$ virus core-related antigen; a marker distinct from viral DNA for monitoring lamivudine treatment. J Viral Hepat 2003;10:324-30.

75 Suzuki F, Miyakoshi H, Kobayashi M, et al. Correlation between serum hepatitis B virus core-related antigen and intrahepatic covalently closed circular DNA in chronic hepatitis B patients. J Med Virol 2009;81:27-33.

76 Wong DK-H, Tanaka Y, Lai C-L, et al. Hepatitis B virus core-related antigens as markers for monitoring chronic hepatitis B infection. J Clin Microbiol 2007:45:3942-7.

77 Wong DK-H, Seto W-K, Cheung K-S, et al. Hepatitis $B$ virus core-related antigen as a surrogate marker for covalently closed circular DNA. Liver Int 2017;37:995-1001.

78 Tada T, Kumada T, Toyoda H, et al. HBcrAg predicts hepatocellular carcinoma development: an analysis using time-dependent receiver operating characteristics. J Hepatol 2016;65:48-56.

79 Tseng T-C, Liu C-J, Hsu C-Y, et al. High level of hepatitis $B$ core-related antigen associated with increased risk of hepatocellular carcinoma in patients with chronic HBV infection of intermediate viral load. Gastroenterology 2019;157:1518-29.

80 Tsuji K, Nishimori H, Matsui T, et al. Hepatitis B virus core-related antigen is a putative predictive marker of hepatocarcinogenesis for the patient with nucleos(t)ide analogues therapy. Kanzo 2009;50:166-7.

81 Honda M, Shirasaki T, Terashima T, et al. Hepatitis B Virus (HBV) Core-Related Antigen During Nucleos(t) ide Analog Therapy Is Related to Intra-hepatic HBV Replication and Development of Hepatocellular Carcinoma. J Infect Dis 2016:213:1096-106.

82 Ando Y, Ishigami M, Ishizu Y, et al. Cumulative incidence and risk factors for the development of hepatocellular carcinoma in patients with chronic hepatitis B who achieved sustained disappearance of viremia by nucleos(t)ide analog treatment. Hepatol Res 2018;48:E240-51.

83 Cheung K-S, Seto W-K, Wong DK-H, et al. Relationship between $\mathrm{HBsAg}, \mathrm{HBcrAg}$ and hepatocellular carcinoma in patients with undetectable HBV DNA under nucleos(t)ide therapy. J Viral Hepat 2017;24:654-61. 